\title{
Subjective cognitive failures and hippocampal volume in elderly with white matter lesions
}

A.G.W. van Norden, MD

W.F. Fick, MSc

K.F. de Laat, MD

I.W.M. van Uden, MSc

L.J.B. van Oudheusden, MSc

I. Tendolkar, MD, PhD

M.P. Zwiers, PhD

F.E. de Leeuw, MD, $\mathrm{PhD}$

Address correspondence and reprint requests to Dr. F.E. de Leeuw, Department of Neurology, Radboud University Nijmegen Medical Centre, Reinier Postlaan 4, PO-box 9101, 6500 HB Nijmegen,

The Netherlands H.deLeeuw@neuro.umcn.nl

\section{ABSTRACT}

Background: Subjective cognitive failures (SCF) and subjective memory failures (SMF) have been reported to be an early predictor of Alzheimer disease (AD) and have been attributed to white matter lesions (WML). Since AD is characterized by hippocampal degeneration, it is surprising that its relation with hippocampal atrophy has been investigated only sparsely. Previous studies on this are rare, limited in sample size, and did not adjust for WML.

Objective: To determine the relation between SCF and hippocampal volume in strata of objective cognitive performance among elderly without dementia with incidental WML.

Methods: The Radboud University Nijmegen Diffusion tensor and MRI Cohort study is a prospective cohort study among 503 subjects with WML aged between 50 and 85 years. All subjects underwent FLAIR and T1 MRI scanning. The amount of SCF and SMF was rated by the Cognitive Failure Questionnaire. Cognitive function was assessed by a cognitive screening battery. Volumetric measures of hippocampus and WML were manually performed. We assessed the relation between hippocampal volume and SCF and SMF adjusted for age, sex, education, depression, intracranial volume, and WML volume.

Results: Subjects with SCF and SMF had lower hippocampal volumes than those without ( $p=$ 0.01 and $p=0.02)$. This was most noteworthy in subjects with good objective cognitive performance $\left(p_{\text {trend }}=0.007\right.$ and $p_{\text {trend }}=0.03$ ), and not in those with poor objective cognitive performance.

Conclusion: Subjective cognitive failures (SCF) are associated with lower hippocampal volume, even in subjects without objective cognitive impairment and independent of white matter lesions. SCF has a radiologic detectable pathologic-anatomic substrate. Neurology ${ }^{\circledR}$ 2008;71:11521159

\section{GLOSSARY}

AD = Alzheimer disease; $\mathbf{A N C O V A}=$ analysis of covariance; $\mathbf{C E S}-\mathbf{D}=$ Center of Epidemiologic Studies-Depression Scale; FLAIR = fluid attenuated inversion recovery; $\mathbf{G M}=$ gray matter; ICV = intracranial volume; $\mathbf{M M S E}=$ Mini-Mental State Examination; RUN DMC = Radboud University Nijmegen Diffusion tensor and MRI Cohort; SCF = subjective cognitive failures; $\mathbf{S E F}=$ subjective executive failures; $\mathbf{S M F}=$ subjective memory failures; $\mathbf{T E}=$ echo time; $\mathbf{T I}=$ inversion time; $\mathbf{T R}=$ repetition time; $\mathbf{W M}=$ white matter; $\mathbf{W M L}=$ white matter lesions.

Clinicians are often confronted with elderly patients who report subjective cognitive complaints including memory complaints such as forgetting appointments in the near future or recent occurrences. Despite considerable controversy, ${ }^{1,2}$ several studies have found a relation between these subjective cognitive complaints and objective cognitive impairment, such as loss of executive and memory function as assessed by neuropsychology in elderly without dementia. ${ }^{3,4}$ More noteworthy, subjective complaints in individuals with normal cognition as assessed by formal neuropsychological testing predict Alzheimer disease (AD) years after initial subjective complaints. ${ }^{5}$ Hence, these subjective complaints, distinguished in memory complaints and

From the Department of Neurology (A.G.W.v.N., W.F.F., K.F.d.L., I.W.M.v.U., L.J.B.v.O., F.E.d.L.), Department of Psychiatry (I.T.), Radboud University Nijmegen Medical Centre, Donders Institute for Brain, Cognition, and Behaviour, and FC Donders Centre for Cognitive Neuroimaging (M.P.Z.), Radboud University Nijmegen, The Netherlands.

Dr. de Leeuw has received a personal clinical fellowship of the Netherlands Organization for Scientific Research (project number: 40-00703-9707197) and a fellowship of the Dutch Brain foundation (H04-12).

Disclosure: The authors report no disclosures. 
executive complaints, could be the earliest sign of cognitive dysfunction and might be a sensitive tool to identify those at risk for AD.

Early in its course, AD is characterized by a slowly progressive memory deficit due to gradual hippocampal degeneration, ultimately resulting in hippocampal atrophy. ${ }^{6}$ The memory deficit is often accompanied by loss of executive function, presumably caused by frontal gray matter atrophy, but also by white matter lesions (WML). ${ }^{7,8}$ Neuropathologic studies indicate that hippocampal atrophy and WML may be present years or even decades before cognitive symptoms become detectable. ${ }^{9-11}$

Depressive symptoms are also often present during early AD. There is an ongoing debate whether these symptoms influence or even cause cognitive complaints or whether a prestage of Alzheimer pathology is responsible for the cognitive complaints, despite spared cognition during formal testing. ${ }^{1,2,4,12}$ However, the presence of depressive symptoms is usually not taken into account in studies that assessed the relation between cognitive complaints, objective cognitive function, and their underlying pathologic substrate.

We hypothesized that subjective memory complaints and subjective executive complaints are already neuroradiologically characterized by hippocampal atrophy and WML, even in subjects without any objective cognitive impairment. Only a few studies have addressed this issue. Two large population-based studies found that WML were related to cognitive complaints, but did not adjust for hippocampal volume. ${ }^{4,12}$ Besides that, WML were rated semiquantitatively or by automated segmentation, potentially leading to underestimation of the actual WML burden. ${ }^{13}$ Conversely, other studies related hippocampal volume to subjective memory complaints, without taking the degree of WML into account. ${ }^{12,14,15}$ In addition, most studies did not adjust for depressive symptoms, being a potential confounder.

We therefore wanted to investigate whether subjective cognitive complaints on both the memory and executive domain were associated with hippocampal and WML volume in 503 in- dependent living healthy elderly with incidental WML.

METHODS Study population. This study is embedded within the Radboud University Nijmegen Diffusion tensor and MRI Cohort (RUN DMC) study. The RUN DMC study prospectively investigates causes and cognitive and motor consequences of longitudinal functional and structural changes in the brain of individuals with incidental WML. Baseline investigations took place in 2006. Consecutive subjects, aged between 50 and 85 years, who visited the neurology outpatient clinic between October 2002 and November 2006 and who underwent routine diagnostic brain imaging, for reasons not related to the cognitive and motor study outcome (including collapses, mild traumatic brain injury, vertigo, chronic head pain, or cranial nerve palsy), were eligible for participation. Exclusion criteria were any abnormality on the routine diagnostic brain imaging that could interfere with the outcome (space occupying lesions, hemorrhages, large-artery infarcts), MRI contraindications, and prevalent dementia. Subjects were selected in strata of age (5 years), sex, and WML severity according to the ARWMC scale. ${ }^{16}$ Upon agreement to participate in the study they underwent an extensive MRI protocol as part of the study on which all MRI measures reported here were based (see below).

In 2006, 1,004 subjects were selected for possible participation. On the basis of MRI contraindications and the other exclusion criteria 299 subjects were excluded. The final sample consisted of 705 subjects of whom 503 agreed to participate (response $71.3 \%$ ). Each participant signed an informed consent. The Medical Review Ethics Committee region ArnhemNijmegen approved the study.

MRI acquisition. All subjects underwent a 1.5 Tesla MRI scanning on the same Magnetom Sonata scanner (Siemens, Erlangen, Germany). The scanning protocol included whole brain T1 three-dimensional MPRAGE imaging (repetition time [TR]/ echo time [TE]/inversion time [TI] 2,250/3.68/850 msec; flip angle $15^{\circ}$; voxel size $1.0 \times 1.0 \times 1.0 \mathrm{~mm}$ ) and fluid attenuated inversion recovery (FLAIR) image (TR/TE/TI 9,000/84/2,200 msec; voxel size $1.0 \times 1.2 \times 6.0 \mathrm{~mm}$ [including gap of $1 \mathrm{~mm}$ ]; number of excitations $=2$ ).

Hippocampus and intracranial volume. One experienced investigator blinded to clinical data, total WML volume, and FLAIR images (I.W.M.v.U.) manually segmented left and right hippocampus on the MPRAGE image using the interactive software program ITK-SNAP. ${ }^{17}$ Anatomic boundaries were coronally determined with neuroanatomic atlases ${ }^{18,19}$ and actual segmentation was performed using a previously published protocol. ${ }^{20}$ In short, segmentation was performed from posterior to anterior. The posterior border of the hippocampus was identified in the slice before the level in which the crurae fornices appeared in full view. The anterior border of the hippocampus was defined as the slice in which the hippocampus was no longer present, and the amygdala fully covered the hippocampus. ${ }^{20-22}$ The superior border was the inferior horn of the lateral ventricle; the inferior border was determined by the white matter. The lateral border was defined by the temporal horn of the lateral ventricle and the white matter adjacent to the hippocampus.

Volumes were calculated for the left and right hippocampus separately by summing all voxel volumes of the segmented areas. Intrarater studies on a random sample of 50 MRI scans showed an intraclass correlation coefficient for the left hippocampus of 0.73 , and for the right hippocampus of 0.79 . 
For the same image, gray (GM) and white matter (WM) tissue and CSF probability maps were computed using SPM5 routines (Wellcome Department of Cognitive Neurology, University College London, UK). Total GM, WM, and CSF volumes were calculated by summing all voxel volumes that had a $p$ $>0.5$ for belonging to the tissue class. Intracranial volume (ICV) was taken as the sum of total GM, WM, and CSF. ${ }^{12}$

WML volume. WML were manually segmented on transversal FLAIR images. WML were defined as hyperintense lesions on FLAIR MRI and not CSF like hypointense lesions on T1weighted image. WML volume was calculated in the same fashion as for the hippocampi. Gliosis surrounding lacunar and territorial infarctions was not considered to be WML. ${ }^{16,23}$ Two trained raters (I.W.M.v.U., L.J.B.v.O.) segmented all scans. For the total WML volume the inter-rater intraclass correlation coefficient was 0.98 in a random sample of 50 scans.

Subjective cognitive failures. Information on subjective cognitive failures (SCF) was assessed by a 15 -item semistructured interview based on the Cognitive Failure Questionnaire ${ }^{4,24}$ (table 1). Responses were added to a sumscore for SCF with a maximum of 25. According to previous studies, subjective

\begin{tabular}{|c|c|c|}
\hline Subjective Cognitive Failures Questionn & $=500)$ & \\
\hline Question & $\begin{array}{l}\text { Score } \\
\text { range }\end{array}$ & $\begin{array}{l}\% \text { with } \\
\text { problems }\end{array}$ \\
\hline \multicolumn{3}{|l|}{ Memory problems } \\
\hline Do you consider yourself as forgetful? & $0-3$ & 54.2 \\
\hline Have you experienced any progression on this item?* & $0-2$ & 56.0 \\
\hline Do you experience word-finding problems? & $0-3$ & 61.8 \\
\hline Have you experienced any progression on this item?* & $0-2$ & 26.7 \\
\hline Do you ever forget names of family members or friends? & $0-1$ & 59.2 \\
\hline Do people tell you that you tell stories twice? & $0-1$ & 39.2 \\
\hline Do you ever forget occurrences of the past 1 or 2 days? & $0-1$ & 32.2 \\
\hline Do you worry about forgetfulness? & $0-1$ & 42.2 \\
\hline $\begin{array}{l}\text { Do you experience hindrance in everyday life because of } \\
\text { forgetfulness? }\end{array}$ & $0-1$ & 37.8 \\
\hline $\begin{array}{l}\text { Do you ever misplace items at odd locations, leave the } \\
\text { stove burning, or forget how to use everyday appliances? }\end{array}$ & $0-1$ & 11.2 \\
\hline Do you ever forget appointments? & $0-1$ & 21.2 \\
\hline $\begin{array}{l}\text { Do you ever lose your way in your neighborhood or do not } \\
\text { recognize a person with whom you are actually well } \\
\text { acquainted? }\end{array}$ & $0-1$ & 10.2 \\
\hline \multicolumn{3}{|l|}{ Related executive problems } \\
\hline $\begin{array}{l}\text { Have you experienced problems with planning of } \\
\text { activities? }\end{array}$ & $0-3$ & 15.2 \\
\hline Have you experienced any progression on this item?* & $0-2$ & 41.7 \\
\hline Do you have concentration problems? & $0-3$ & 39.6 \\
\hline Have you experienced any progression on this item?* & $0-2$ & 48.1 \\
\hline Do you think or act more slowly than you used to? & $0-3$ & 47.4 \\
\hline Have you experienced any progression on this item?* & $0-2$ & 52.1 \\
\hline \multicolumn{3}{|l|}{ Remaining problems } \\
\hline Do you feel more exhausted than you used to? & $0-1$ & 30.2 \\
\hline Do you ever feel so depressed that you lose interest in life? & $0-1$ & 22.8 \\
\hline
\end{tabular}

*Percentage of participants with subjective failure on the accompanying item who reported little (score 1) or obvious (score 2) progression over the past 5 years on that particular item. failure in remembering, word finding, planning, concentration, or slowness in thought had a higher weight in the sumscores (score range of $0-3$ : none, mild, moderate, severe) than the 10 other items $(0-1)$. SCF were considered present when a subject reported at least one moderate problem (score 2 or higher) on an item having a score range of $0-3$ or a score of 1 on dichotomous items. ${ }^{4}$ In addition, we assessed whether subjects reported progression of remembering, word finding, planning, concentration, or slowness of thought over the past 5 years (part of the Subjective Cognitive Failures Questionnaire, table 1). Progression was defined as obvious progression of at least one failure or little progression on more than one of these failures. ${ }^{4}$

SCF were subdivided into subjective memory failures (SMF) and subjective executive failures (SEF). SMF were considered present if failures were reported in 1 of the 10 items concerning memory problems; SEF were considered present if failures in planning, concentration, and slowness in thought were reported. ${ }^{4}$

Objective cognitive performance. Cognitive performance was assessed by a standardized neuropsychological test battery that has been used in other large-scale epidemiologic studies of cognition in healthy elderly. ${ }^{8,25,26}$ The tests were administered by two trained investigators (A.G.W.v.N., K.F.d.L.) and included the Mini-Mental State Examination (MMSE), ${ }^{27}$ a 15 -word verbal learning test, ${ }^{28}$ an abbreviated Stroop test consisting three subtasks, ${ }^{29}$ the Paper and Pencil Memory Scanning Task, ${ }^{30}$ a verbal fluency task in which as many animals and as many jobs as possible had to be named within 60 seconds, ${ }^{31}$ and the SymbolDigit Substitution Task, which is a modified version of the Symbol Digit Modalities Test. ${ }^{32}$

Performance across tests was made comparable by transforming the raw test scores into $Z$-scores as described elsewhere. ${ }^{33}$ $Z$-scores of the tests that had higher scores representing worse performance, like the speed score, were inverted $(-Z)$. From these $Z$-scores we calculated compound scores for cognitive function, memory function, and executive function, as described previously. ${ }^{8}$ In short, compound score for cognitive function was calculated as the mean of the $Z$-scores of the one-letter subtask of the Paper-and-Pencil Memory Scanning Task, the reading subtask of the Stroop test, the Letter-Digit Substitution Task, the added score of the three learning trials of 15 -word verbal learning test, and the delayed recall of this test. ${ }^{8}$ A compound score for memory function was calculated by taking the mean of two $Z$-scores of the 15-word verbal learning test: one for the added scores on the three learning trials, and one for the delayed recall. ${ }^{8}$ The compound score for executive function was calculated as the mean of the Z-scores of the verbal fluency test, the SymbolDigit Substitution Task, and the interference subtask of the Stroop test.

If the test assistant encountered problems, a code was given for test status and the result was not used in the calculation of the $Z$-scores. Separate codes were given for lack of motivation (2.7\%), presence of a physical handicap (1.2\%), or deviation from the instructions (2.9\%). For 465 subjects (93\%), reliable compound scores could be calculated.

Other measurements. The following characteristics were considered as possible confounders: age, sex, education (according to Verhage), ${ }^{34}$ and depressive symptoms. Depressive symptoms were considered present when a subject had a score $\geq 16$ on the Center of Epidemiologic Studies-Depression Scale (CESD) ${ }^{35,36}$ and/or the use of antidepressive medication. ${ }^{36}$ ICV was also considered as a potential confounder. 


\begin{tabular}{|c|c|c|c|c|}
\hline \multirow[t]{2}{*}{ subjective cognitive failures } & \multirow[b]{3}{*}{ Total $(n=500)$} & he SCF Questi & with or without & \multirow[b]{3}{*}{$p^{*}$} \\
\hline & & Subjective cos & failures & \\
\hline Characteristic & & Yes $(n=453)$ & No $(n=47)$ & \\
\hline Age, y & $65.6(8.8)$ & $66.1(8.7)$ & $61.1(8.7)$ & $<0.001$ \\
\hline Male/female & $281 / 219$ & $251 / 202$ & $30 / 17$ & 0.244 \\
\hline Subjects with only primary education & 47 (9.4\%) & 45 (9.9\%) & $2(4.3 \%)$ & 0.654 \\
\hline MMSE & $28.2(1.6)$ & $28.1(1.6)$ & $28.4(1.6)$ & 0.249 \\
\hline CES-D & $10.9(9.4)$ & $11.4(9.3)$ & $6.1(9.4)$ & $<0.001$ \\
\hline Subjects with depressive symptoms ${ }^{+}$ & 166 (33\%) & $160(35 \%)$ & $6(13 \%)$ & 0.003 \\
\hline Subjects with CES-D $\geq 16$ & $139(28 \%)$ & 135 (30\%) & $4(9 \%)$ & 0.003 \\
\hline Subjects with antidepressive medication & $62(12 \%)$ & $59(13 \%)$ & $3(6 \%)$ & 0.271 \\
\hline \multicolumn{5}{|l|}{ Subjective cognitive failures (SCF) } \\
\hline Sumscore on the SCF questionnaire & $8.5(5.7)$ & $9.3(5.2)$ & $0.5(5.2)$ & $<0.001$ \\
\hline Subjects with SCF & 453 (91\%) & & & \\
\hline Sumscore of subquestionnaire on SMF & 5.4 (3.5) & $5.9(3.1)$ & 0.4 (3.1) & $<0.001$ \\
\hline Subjects with SMF & 442 (88\%) & & & \\
\hline Sumscore of subquestionnaire on SEF & $2.5(2.3)$ & $2.8(2.3)$ & $0.2(2.2)$ & $<0.001$ \\
\hline Subjects with SEF & 304 (61\%) & & & \\
\hline Subjects with SCF reporting its progression & $194(43 \%)$ & & & \\
\hline
\end{tabular}

Values are mean (SD) or $\mathrm{n}(\%)$.

*Analysis of covariance adjusted for age and sex, where appropriate.

${ }^{+}$Defined as CES-D scores $\geq 16$ and/or the use of antidepressive medication $(n=498)$.

MMSE = Mini-Mental State Examination; CES-D = Center of Epidemiologic Studies-Depression scale; SMF = subjective memory failures; SEF = subjective executive failures.

Statistical analysis. Statistical analyses were performed with the use of SPSS 14.0 for Windows. Demographic characteristics were compared between subjects with or without SCF by sexand age-adjusted analysis of covariance (ANCOVA) (by so called "forced entry") (table 2).

Mean hippocampal and WML volume and the proportion of subjects with severe WML (highest quintile) ${ }^{4}$ were calculated for subjects with or without SCF, SMF, or SEF by ANCOVA (table 3). All assumptions for ANCOVA were verified for each analysis.

Next, we calculated the mean hippocampal and WML volume in subjects with and without SCF by severity of the failures (ANCOVA). Subjects who reported no SCF, as defined earlier, were considered having "no SCF." The group with SCF was dichotomized at the upper tertile of the SCF score, which reflected "severe SCF"; the lower two tertiles were defined as "moderate SCF." SMF and SEF were categorized accordingly.

To investigate whether the level of objective cognitive performance modified the association between hippocampal or WML volume and severity of SCF, we analyzed this relation stratified by objective performance, according to tertiles of the compound score for cognitive function (poor, moderate, or good). ${ }^{4}$

Finally, we investigated whether progression of failures was related to hippocampal or WML volume.

For the trend analysis of the ANCOVA results, groups of severity of failures (none, moderate, severe) were considered as a continuous variable in a multiple linear regression model. Age, sex, education, depressive symptoms, ICV, and where appropri- ate WML volume and hippocampal volume were put together into the model (so called "forced entry").

RESULTS Of the 503 subjects, one was excluded because of an automatic segmentation problem and two because of an incomplete SCF questionnaire. The presence of depressive symptoms was assessed in 498 subjects. Demographic characteristics are shown in table 2. Subjects reporting SCF were older $(p<$ $0.001)$ and had more depressive symptoms $(p=$ 0.003 ) adjusted for age and sex. Subjective failures on all three domains (SCF, SMF, and SEF) were associated with reduced objective performance, independent of depressive symptoms, WML, and hippocampal volume $(p<0.01)$.

Table 3 illustrates that subjects with SCF had a lower hippocampal volume than those without $(p=$ $0.01)$. Subsequent analysis showed that this was also evident in subjects with SMF $(p=0.01)$ and SEF $(p=0.07)$. Additional adjustment for WML volume did not significantly change the effect. No relation was found between SCF and WML volume $(p>$ 0.1 ), except for subjects reporting SEF who more often had severe WML (25\%) than those who did not $(15 \% ; p=0.05)$. 


\begin{tabular}{|cccc|}
\hline Table 3 & $\begin{array}{l}\text { Mean hippocampal and WML volume (SD) for subjects with and } \\
\text { without subjective cognitive failures (SCF), subjective memory } \\
\text { failures (SMF), and subjective executive failures (SEF)* }\end{array}$ \\
\hline SCF & Hippocampal volume & WML volume & No. (\%) severe WML \\
Present & $6.7(0.9)$ & $14.4(19.2)$ & $94(21)$ \\
Absent & $7.1(1.1)^{+}$ & $14.6(12.0)$ & $6(13)$ \\
SMF & & $14.4(19.4)$ & $91(21)$ \\
Present & $6.7(1.0)$ & $14.3(11.6)$ & $9(16)$ \\
Absent & $7.0(1.0)^{+}$ & & $71(24)$ \\
SEF & & $15.1(19.8)$ & $29(15)^{\ddagger}$ \\
Present & $6.7(0.9)$ & $13.4(16.5)$ & \\
Absent & $6.9(1.0)$ & &
\end{tabular}

*Table represents $\mathrm{mL}$, adjusted for age, sex, education, depressive symptoms, intracranial volume, WML volume, and hippocampal volume where appropriate.

${ }^{+} p<0.02$.

$\neq p=0.05$.

$\mathrm{WML}=$ white matter lesions. asking for it, potentially resulting in a higher degree of reported failures. Another explanation could be that all subjects were recruited through our outpatient clinic, rather than being community-based. Consequently, we have included people who once sought medical help and who therefore are more likely to express complaints simply because they had visited an outpatient clinic. Nonetheless, our study cohort represents a typical outpatient population that was being investigated for reasons that frequently lead to the discovery of WML among healthy, independent living elderly. We intentionally included subjects with incidental WML as advising these subjects reflect everyday clinical practice. This advice has been limited by the fact that most studies on this topic have a different design. It is important to realize that most knowledge on causes and consequences of WML is based on either population-based studies or patients with more advanced stages of dementia, and may not be applicable to patients with incidental WML. These studies have improved our understanding on the etiology and consequences of WML, but results may not be applicable to individuals who visit an outpatient clinic. Acquiring more data on causes and consequences of WML in this particular group is an important goal of the RUN DMC study. jects with severe, moderate, and no SCF. The difference in hippocampal volume across these different groups with SCF was most apparent in subjects with good cognitive performance $\left(p_{\text {trend }}=0.005\right)$. This relation was also found for $\operatorname{SMF}\left(p_{\text {trend }}=\right.$ 0.024; figure 2), with borderline significance for subjects with moderate memory performance $\left(p_{\text {trend }}=0.076\right)$. Additional adjustment for WML did not change the magnitude of the associations. These relations were not found for WML volume, in neither of the objective cognitive strata nor in the whole group analysis.

Progression of failures was not associated with hippocampal volume, nor with WML volume.

DISCUSSION We found that SCF were associated with lower hippocampal volume, independent of depressive symptoms and WML volume, in elderly individuals with incidental WML. This relation was most evident in subjects with intact cognition as revealed by neuropsychological testing.

In our study the proportion of subjects reporting SCF (91\%) and SMF (88\%) was higher than in other studies, which reported percentages between 26 and 72\%.3.,4,12 A possible explanation for our relatively high frequency might be the method used to determine SCF. SCF were not identified through spontaneous reporting, but by actively

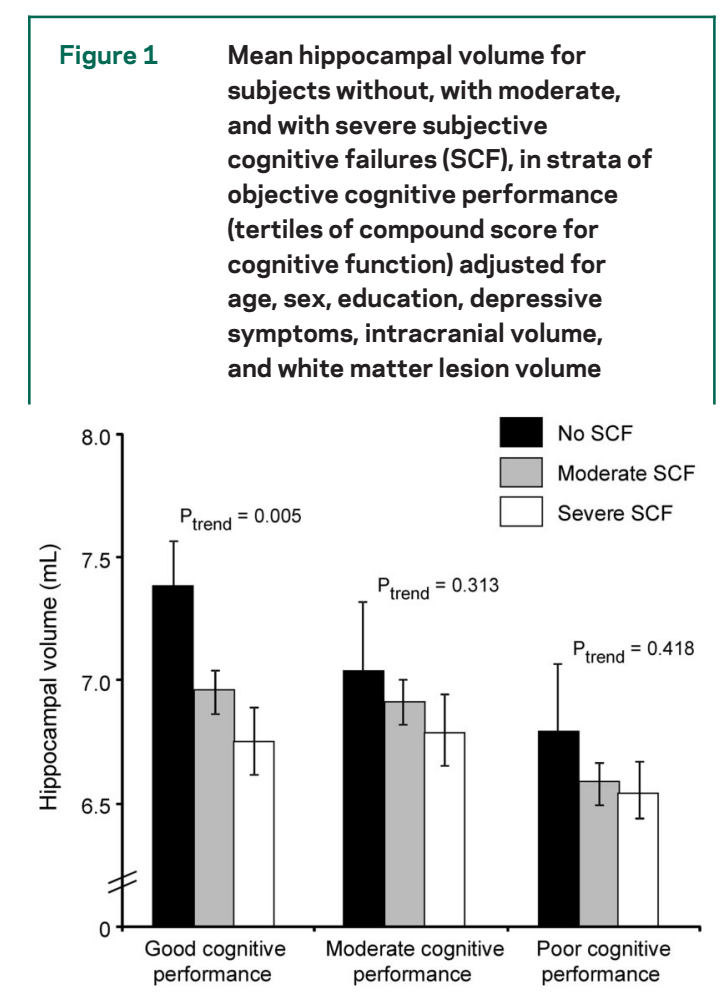

Subjects who reported no SCF $($ good $n=26$; moderate $n=$ 11 ; poor $n=10)$; subjects with moderate $S C F(\operatorname{good} n=90$; moderate $n=100$; poor $n=91$ ); subjects with severe SCF (good $n=40$; moderate $n=44$; poor $n=54$ ). 


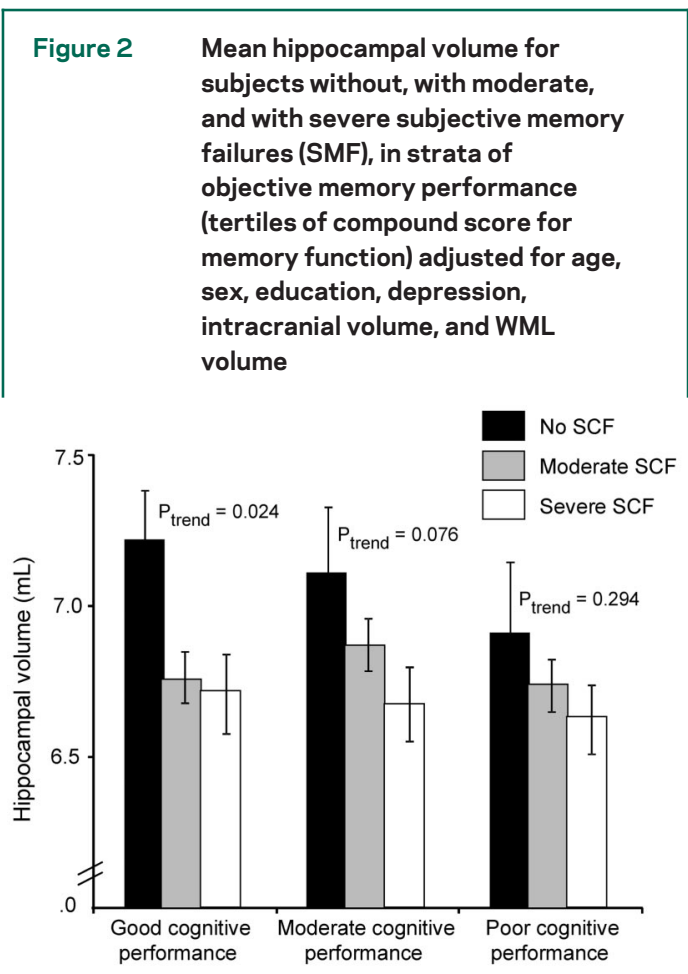

Subjects who reported no SMF (good $\mathrm{n}=28$; moderate $\mathrm{n}=15$; poor $\mathrm{n}=15$ ); subjects with moderate SMF (good $\mathrm{n}=97$; moderate $\mathrm{n}=95$; poor $\mathrm{n}=94$ ); subjects with severe SMF $($ good $\mathrm{n}=39$; moderate $\mathrm{n}=52$; poor $n=54)$.

A third explanation for the difference in SCF reporting is that the high percentage of SCF may be related to the relatively high proportion of subjects reporting depressive symptoms (33\%) in our cohort compared to percentages reported in a systematic review $(0.4-35 \%),{ }^{37}$ and we were able to adjust for that.

The strength of this study includes the fact that it is a large, single center study with a high response; its structured and extensive assessment of cognitive functioning performed by only two investigators; the use of a single MR scanner; the use of a reliable and sensitive volumetric assessment of WML instead of a visual rating scale $^{13}$; the use of a single expert who segmented the hippocampus with high inter-rater agreement, blinded to all clinical and radiologic data; and the opportunity of extensive adjustment for possible confounders.

Our results are in agreement with two recent studies, which reported reduced hippocampal volumes in subjects with memory complaints as compared to controls. ${ }^{12,14,15}$ The unique aspect of our study was the inclusion of depressive symptoms and WML volume as covariates, since they are related to SCF, ${ }^{2,4,25}$ and to hippocampal atrophy. ${ }^{38}$

Importantly, the relation between lower hippocampal volume and SCF and SMF was demon- strated in subjects with good objective performance. This may provide an underlying pathoanatomic explanation for the frequently observed SCF and may therefore function as an early marker for the development of diseases characterized by memory loss, including $\mathrm{AD}$ and its attendant neuropathologic substrates such as hippocampal atrophy. ${ }^{4,14,15}$ Since memory impairment is mainly related to hippocampal neurodegeneration, ${ }^{6,39}$ it is conceivable that SCF and SMF are also primarily related to hippocampal atrophy rather than WML. As lower hippocampal volume is associated with future conversion to $\mathrm{AD},{ }^{40} \mathrm{SCF}$ can serve as an early predictor of $\mathrm{AD}$, even in the absence of objective cognitive impairment.

In our study, SCF and SMF were not related to WML volume. This in accordance with another study, ${ }^{3}$ whereas other studies did report an association between WML and cognitive complaints.,12,25 However, some methodologic considerations of these studies should be discussed. Most importantly, they did not adjust for hippocampal volume, which obviously appears to be related to SCF and SMF. In addition, the first study ${ }^{25}$ had a relatively small sample $(n=60)$ and in the other study ${ }^{4}$ the severity of WML was scored semiquantitatively, potentially leading to an underestimation of the actual WML burden. This effect may especially be present among those with severe WML, because of ceiling effects in semiquantitative rating scales. Yet, in our study severe WML were more frequently observed in subjects reporting SEF than those who did not. This is in line with previous studies that found WML to be primarily related to executive functions and speed/motor control domains. ${ }^{7,36}$

We found no relation between hippocampal atrophy and SCF or SMF in subjects with moderate or poor objective cognitive performance; this may be due to a type II error. A previous study found a similar association for WML in relation to reported progression of SCF. ${ }^{4}$ It has been suggested that the relation between SCF and objective performance may be disproportional in subjects with poor cognitive performance, simply because of their cognitive impairment and inability to judge their own cognitive function.

Subjective cognitive failures may already have a radiologic fingerprint with an underlying pathoanatomic explanation. Future studies should identify whether progression of failures coincides with these radiologic observations and whether this parallels objective cognitive decline.

Received April 22, 2008. Accepted in final form July 1, 2008. 


\section{REFERENCES}

1. Schofield PW, Jacobs D, Marder K, Sano M, Stern Y. The validity of new memory complaints in the elderly. Arch Neurol 1997;54:756-759.

2. O'Connor DW, Pollitt PA, Roth M, Brook PB, Reiss BB. Memory complaints and impairment in normal, depressed, and demented elderly persons identified in a community survey. Arch Gen Psychiatry 1990;47: 224-227.

3. Miranda B, Madureira S, Verdelho A, et al. Self-perceived memory impairment and cognitive performance in an elderly independent population with age-related white matter changes. J Neurol Neurosurg Psychiatry Epub 2007 Dec 12 .

4. de Groot JC, de Leeuw FE, Oudkerk M, Hofman A, Jolles J, Breteler MM. Cerebral white matter lesions and subjective cognitive dysfunction: the Rotterdam Scan Study. Neurology 2001;56:1539-1545.

5. Schmand B, Jonker C, Hooijer C, Lindeboom J. Subjective memory complaints may announce dementia. Neurology 1996;46:121-125.

6. O'Brien JT, Desmond P, Ames D, Schweitzer I, Chiu E, Tress B. Temporal lobe magnetic resonance imaging can differentiate Alzheimer's disease from normal ageing, depression, vascular dementia and other causes of cognitive impairment. Psychol Med 1997;27:12671275 .

7. Ylikoski R, Ylikoski A, Erkinjuntti T, Sulkava R, Raininko $\mathrm{R}$, Tilvis $\mathrm{R}$. White matter changes in healthy elderly persons correlate with attention and speed of mental processing. Arch Neurol 1993;50:818-824.

8. de Groot JC, de Leeuw FE, Oudkerk M, et al. Cerebral white matter lesions and cognitive function: the Rotterdam Scan Study. Ann Neurol 2000;47:145-151.

9. Dickerson BC, Goncharova I, Sullivan MP, et al. MRIderived entorhinal and hippocampal atrophy in incipient and very mild Alzheimer's disease. Neurobiol Aging 2001; 22:747-754

10. de Groot JC, de Leeuw FE, Oudkerk M, et al. Periventricular cerebral white matter lesions predict rate of cognitive decline. Ann Neurol 2002;52:335-341.

11. Longstreth WT Jr, Manolio TA, Arnold A, et al. Clinical correlates of white matter findings on cranial magnetic resonance imaging of 3301 elderly people: The Cardiovascular Health Study. Stroke 1996;27:1274-1282.

12. Stewart R, Dufouil C, Godin O, et al. Neuroimaging correlates of subjective memory deficits in a community population. Neurology 2008;70:1601-1607.

13. van Straaten EC, Fazekas F, Rostrup E, et al. Impact of white matter hyperintensities scoring method on correlations with clinical data: the LADIS study. Stroke 2006;37: 836-840.

14. Jessen F, Feyen L, Freymann K, et al. Volume reduction of the entorhinal cortex in subjective memory impairment. Neurobiol Aging 2006;27:1751-1756.

15. van der Flier WM, van Buchem MA, WeverlingRijnsburger AW, et al. Memory complaints in patients with normal cognition are associated with smaller hippocampal volumes. J Neurol 2004;251:671-675.

16. Wahlund LO, Barkhof F, Fazekas F, et al. A new rating scale for age-related white matter changes applicable to MRI and CT. Stroke 2001;32:1318-1322.
17. Yushkevich PA, Piven J, Hazlett HC, et al. User-guided $3 \mathrm{D}$ active contour segmentation of anatomical structures: significantly improved efficiency and reliability. Neuroimage 2006;31:1116-1128.

18. Mai J, Paxinos G, Voss T. Atlas of the Human Brain. 3rd ed. Elsevier Inc.; 2007.

19. Duvernoy H. The Human Hippocampus: Functional Anatomy, Vascularization and Serial Sections with MRI. New York: Springer-Verlag; 1997.

20. Geuze E, Vermetten E, Bremner JD. MR-based in vivo hippocampal volumetrics: 2. Findings in neuropsychiatric disorders. Mol Psychiatry 2005;10:160-184.

21. General Brain Segmentation: Method and Utilization, Version 3. Center for Morphometric Analysis; 2004.

22. van de Pol LA, Hensel A, van der Flier WM, et al. Hippocampal atrophy on MRI in frontotemporal lobar degeneration and Alzheimer's disease. J Neurol Neurosurg Psychiatry 2006;77:439-442.

23. Herve D, Mangin JF, Molko N, Bousser MG, Chabriat H. Shape and volume of lacunar infarcts: a 3D MRI study in cerebral autosomal dominant arteriopathy with subcortical infarcts and leukoencephalopathy. Stroke 2005;36:23842388.

24. Broadbent DE, Cooper PF, FitzGerald P, Parkes KR. The Cognitive Failures Questionnaire (CFQ) and its correlates. Br J Clin Psychol 1982;21:1-16.

25. Minett TS, Dean JL, Firbank M, English P, O’Brien JT. Subjective memory complaints, white-matter lesions, depressive symptoms, and cognition in elderly patients. Am J Geriatr Psychiatry 2005;13:665-671.

26. Madureira S, Verdelho A, Ferro J, et al. Development of a neuropsychological battery for the Leukoaraiosis and Disability in the Elderly Study (LADIS): experience and baseline data. Neuroepidemiology 2006;27:101-116.

27. Folstein MF, Folstein SE, McHugh PR. "Mini-mental state": a practical method for grading the cognitive state of patients for the clinician. J Psychiatr Res 1975;12:189-198.

28. Brand N, Jolles J. Learning and retrieval rate of words presented auditorily and visually. J Gen Psychol 1985;112:201-210.

29. Stroop J. Studies of interference in serial verbal reactions. J Exp Psychol 1935;18:643-662.

30. Sternberg S. Memory-scanning: mental processes revealed by reaction-time experiments. Am Sci 1969;57:421-457.

31. Welsh KA, Butters N, Mohs RC, et al. The Consortium to Establish a Registry for Alzheimer's Disease (CERAD): Part V: a normative study of the neuropsychological battery. Neurology 1994;44:609-614.

32. Lezak M. Neuropsychological Assessment. 3rd ed. New York: Oxford University Press; 1995.

33. van Boxtel MP, Buntinx F, Houx PJ, Metsemakers JF, Knottnerus A, Jolles J. The relation between morbidity and cognitive performance in a normal aging population. J Gerontol A Biol Sci Med Sci 1998;53:M147-M154.

34. Verhage F. Intelligentie en leeftijd [Intelligence and age]. Assen: Van Gorcum; 1964.

35. Radloff LS. The CES-D Scale: a self-report depression scale for research in the general population. App Psychol Meas 1977;1:385-401.

36. de Groot JC, de Leeuw FE, Oudkerk M, Hofman A, Jolles J, Breteler MM. Cerebral white matter lesions and depressive symptoms in elderly adults. Arch Gen Psychiatry 2000;57:1071-1076 
37. Beekman AT, Copeland JR, Prince MJ. Review of community prevalence of depression in later life. Br J Psychiatry 1999;174:307-311.

38. Videbech P, Ravnkilde B. Hippocampal volume and depression: a meta-analysis of MRI studies. Am J Psychiatry 2004;161:1957-1966.
39. Braak H, Braak E. Neuropathological stageing of Alzheimer-related changes. Acta Neuropathol 1991;82: 239-259.

40. Jack CR Jr, Petersen RC, Xu YC, et al. Prediction of AD with MRI-based hippocampal volume in mild cognitive impairment. Neurology 1999;52:1397-1403.

\section{Place Yourself Among the Best and Brightest in Neurology}

Apply for 2009 AAN Annual Meeting Awards by November 3, 2008

Apply for a 2009 AAN Annual Meeting Award and you and your work could be recognized along with some of the best and brightest students, residents, researchers, and historians in neurology during the Awards Luncheon at the 61st Annual Meeting. Open to AAN Members and nonmembers. Visit www.aan.com/awards today!

And don't forget that the deadline to submit scientific abstracts for the 2009 Annual Meeting is also November 3. Learn more at www.aan.com/abstracts. 